\title{
IN VITRO EVALUATION OF FUNGAL ISOLATES AND NUTRIENT AMENDMENTS FOR ENHANCING APPLE LEAF DECAY
}

\author{
K. TSHOMO ${ }^{1}$, M. WALTER ${ }^{2}$, A. STEWART ${ }^{1}$ and M.V. JASPERS ${ }^{1}$ \\ ${ }^{1}$ Soil, Plant and Ecological Sciences Division, PO Box 84, Lincoln University \\ ${ }^{2}$ HortResearch, PO Box 51, Lincoln
}

Corresponding author: Jaspersm@Lincoln.ac.nz

\begin{abstract}
Primary spread of apple black spot is by ascospores produced from over-wintering apple leaf litter. To find effective degraders of litter, an in vitro trial screened 59 fungal isolates for the ability to colonise sterilised, senesced apple leaf discs. The isolates of Aureobasidium, Alternaria, Chaetomium, Coniothyrium, Epicoccum, Fusarium, Phoma, Trichoderma and Ulocladium spp. had originated from the phylloplane or leaf litter of fruit crops. The white-rot basidiomycete isolates were from fruiting bodies on native beech, poplar and fruit trees. The 18 isolates that colonised leaf discs most rapidly were further tested, with five nutrient leaf amendments, for their biodegradation activity on leaf discs. After incubation at $10^{\circ} \mathrm{C}$ for 9 weeks, the most effective isolates of Trametes versicolor, Phoma, Epicoccum and Chaetomium spp. caused 54, 39, 37 and 23\% weight reduction, respectively, while the leaf amendments, urea and the mixture of Mycorrcin ${ }^{\mathrm{TM}}$ and Digester ${ }^{\mathrm{TM}}$, caused 29 and 20\% reduction, respectively. These treatments were selected for evaluation in a field trial.
\end{abstract}

Keywords: Venturia inaequalis, apple black spot, saprophytic fungi, leaf degradation.

\section{INTRODUCTION}

Apple black spot, or apple scab as it is known in some countries, is the most economically important disease in apples worldwide. The disease cycle of the pathogen, Venturia inaequalis (Cooke) Wint., includes a primary, over-wintering stage in infected leaf litter, from which ascospores are ejected in spring, and a secondary, repeating imperfect stage, which occurs on fruit and leaves from spring to autumn. Both stages require moist weather and young tissues for successful infection and these are most common in spring when ascospores are released. The amount of primary inoculum available in orchards in spring is therefore a pivotal factor in disease development during the whole growing season (MacHardy 1996).

Control of apple black spot in developed countries is largely by fungicide sprays, which are applied whenever the monitored weather conditions forecast periods of apple black spot infection potential (Beresford \& Manktelow 1994). However, worldwide pressure for more sustainable crop production systems has led to greater emphasis being placed on integrated pest management programmes, which use a range of control strategies that target different phases of the pathogen's development. In apple black spot, ascospore production could be prevented if all over-wintering leaves were removed, but under commercial orchard conditions this is not practical (MacHardy 1996). Another way of achieving this would be to ensure complete degradation of infected leaf litter before the next spring. The use of naturally occurring saprophytic fungi to enhance apple leaf degradation and to antagonise $V$. inaequalis has been demonstrated in Canadian laboratory (Philion et al. 1997; Ouimet et al. 1997) and field studies (Carrisse et al. 2000). Application of urea in autumn has also been reported to enhance degradation of apple leaf litter (Burchill 1968) and to reduce production of ascospores (Beresford et al. 2000; Carisse et al. 2000). The aim of this project was to screen a range of New Zealand isolates of saprophytic fungi, in combination with several nutrient treatments, for their ability to degrade apple leaf litter. 


\section{MATERIALS AND METHODS \\ Preparation of isolates and leaf discs}

The 59 fungal isolates selected were from the genera/types Aureobasidium, Alternaria, Chaetomium, Coniothyrium, Epicoccum, Fusarium, Phoma, Trichoderma, Ulocladium and the basidiomycete white-rot fungi. The white-rot isolates had originated from fruiting bodies on native beech, poplar and fruit trees, and the other isolates were from the phylloplane or leaf litter under fruit crops. Isolates were obtained from the culture collections of Rouke Bakker and the Plant Pathology Group at Lincoln University, and from HortResearch, Lincoln. All fungal isolates were grown on potato dextrose agar (Oxoid), at $20^{\circ} \mathrm{C}$ with a $12 \mathrm{~h}$ diurnal light cycle. The inoculum for each isolate was prepared from five $1.4 \mathrm{~cm}$ diameter plugs cut from the actively growing front of a 7 day old culture. These were homogenised in a sterile plastic bag with $50 \mathrm{ml}$ of sterilised water containing $50 \mu \mathrm{l}$ Tween 20 , using a stomacher laboratory blender, as described by Philion et al. (1997).

Senescing apple leaves were collected from an unsprayed Red Delicious block in the research orchard at Lincoln University. Leaf discs, $1.3 \mathrm{~cm}$ in diameter, were cut from around the lower edge of leaf blades to avoid large veins, since these areas had previously been found to provide discs of relatively uniform weight (mean disc weight $3.5 \mathrm{mg} \pm$ $0.38 \mathrm{mg}$ (SD) from 10 samples of 10 discs). The discs were stored at $4^{\circ} \mathrm{C}$ for up to 2 weeks and then were sterilised by gamma radiation at $27.8 \mathrm{kGy}$ by Schering-Plough Animal Health Ltd, Wellington.

\section{Screen 1}

The sterilised leaf discs were placed on $2 \%$ water agar with five discs per Petri dish and two Petri dishes per isolate. The discs were each inoculated with a $50 \mu \mathrm{l}$ drop of culture suspension. Discs were then incubated for 7 days at $20^{\circ} \mathrm{C}$ in a $12 \mathrm{~h}$ diurnal light cycle, on trays lined with moist paper towels and loosely wrapped in new plastic bags. The diameters of the developing colonies were recorded daily for 4 days and then at day 7. Mean colony diameters were used as a basis for selecting isolates for a further screen, and as many genera as possible were represented.

\section{Screen 2}

Eighteen fungal isolates (Table 1) and five leaf amendments were screened for their efficacy at degrading senesced apple leaf discs, at two incubation temperatures, 10 and $20^{\circ} \mathrm{C}$, in a $18 \times 5 \times 2$ factorial experiment. All leaf amendments were tested at their recommended concentrations, made in sterilised water containing 0.025\% Citowett $^{\mathrm{TM}}$ (BASF New Zealand Limited, Auckland). The leaf amendments were:

1. Bio-Start ${ }^{\mathrm{TM}}$, a mixture of two formulations produced by Bio-Start Ltd, Auckland. Mycorrcin $^{\mathrm{TM}}$ and Digester ${ }^{\mathrm{TM}}$ were added at $270 \mu \mathrm{l}$ and $85 \mu \mathrm{l}$, respectively, into $100 \mathrm{ml}$ water. Both were described as products of bacterial fermentations based on a range of natural food substrates.

2. Simply Organic ${ }^{\mathrm{TM}}$, an organic fish-based foliar nutrient produced by Folio Feed Fertiliser Ltd. Dunedin, at $5 \mathrm{ml} / 100 \mathrm{ml}$ water. It contained nitrogen $(0.81 \% \mathrm{w} / \mathrm{v}=5 \%$ protein $)$ and fish oils $(4.1 \% \mathrm{w} / \mathrm{w}, 3.9 \% \mathrm{w} / \mathrm{v})$, as well as other nutrients and trace elements. The concentrations of these, shown as $\mathrm{mg} /$ litre in parentheses, were $\mathrm{Zn}(5), \mathrm{Cu}$ (0.6), $\mathrm{Fe}$ (0.7), Mn (0.7), Ca (1215), P (828), Cl (934), $\mathrm{S}$ (324), $\mathrm{Na}$ (384), Mg (93), K (1430), Pb (3), Hg (<1), Cd (<1) and As (<1).

3. Vertex ${ }^{\mathrm{TM}}$, a foliar nutrient produced by Headland Agrichemicals, Cambridge, New Zealand, at $200 \mu \mathrm{l} / 100 \mathrm{ml}$ water. It contained N (12\%), P (8\%), K (2\%), $\mathrm{S}(1.5 \%)$ and $\mathrm{Mg}(0.8 \%)$, and the trace elements Bo (80 ppm), Zn (60 ppm), $\mathrm{Ni}(50 \mathrm{ppm})$ and $\mathrm{Mb}(10 \mathrm{ppm})$.

4. Urea at $5 \mathrm{~g} / 100 \mathrm{ml}$ water.

5. Water (containing $0.025 \%$ Citowett).

For each combination of factors, there were four Petri dishes, each dish containing four leaf discs. To retain moisture during the long period of incubation, each $25 \mathrm{~mm}$ deep dish was filled with $25 \mathrm{ml}$ of sterilised tap water and $50 \mathrm{ml}$ fine grade (2-3 mm) vermiculite, which had been autoclaved twice for 30 minutes at $121^{\circ} \mathrm{C}$, with 
an intervening $24 \mathrm{~h}$ period at room temperature. The leaf discs were soaked for $5 \mathrm{~min}$ in their nutrient solutions, using heat-sterilised, stainless steel tea strainers, and then drained and placed on top of the vermiculite in an equidistant layout. After inoculation with $50 \mu \mathrm{l}$ per disc of mycelial suspension, the Petri dishes were incubated at room temperature for 1 week. Dishes were stacked in a randomised block design and incubated in $10^{\circ} \mathrm{C}$ and $20^{\circ} \mathrm{C}$ temperature rooms. In the $20^{\circ} \mathrm{C}$ treatment, the dishes were observed to be drying out after 4 weeks and a further $25 \mathrm{ml}$ aliquot of sterilised tap water was added to each.

After 8 weeks incubation, the leaf discs were cleared of vermiculite particles and fungal mycelium, and dried at $50^{\circ} \mathrm{C}$ for $48 \mathrm{~h}$, the original groups of four discs from each dish being kept together. The weights of the four disc groups were analysed by analysis of variance and significance comparisons between treatments were made using Fisher's LSD test $(\mathrm{P}=0.05)$.

\section{Screen 1}

\section{RESULTS}

The rate at which fungal isolates grew on leaf discs differed within and between genera, with some isolates failing to grow, even when inoculation was repeated on fresh leaf discs. For those isolates that did grow well, 3 days incubation was sufficient to differentiate between the fast and slow growing isolates. The 18 fastest growing isolates were selected for a second screen.

\section{Screen 2}

After 9 weeks incubation, weight losses of leaf discs were significantly greater at $10^{\circ} \mathrm{C}$ than at $20^{\circ} \mathrm{C}(\mathrm{P}=0.001)$. There were significant differences between fungi $(\mathrm{P}=0.001)$, and significant interactions between fungal isolates and temperature $(\mathrm{P}=0.001)$ and between fungal isolates and nutrient amendments $(\mathrm{P}=0.045)$. The isolates that caused the greatest weight reduction were the Trametes, Phoma and Epicoccum spp. (Table 1). The discs with the Trametes spp. were most heavily colonised, being covered with thick mats of hyphal growth that grew beyond the leaf discs onto the vermiculite. The leaf discs were also quite degraded appearing pale yellow and almost transparent. Leaf discs treated with Epicoccum and Ulocladium isolates also showed conspicuous mycelium, mostly on disc edges.

The leaf amendments differed significantly in their overall effects $(\mathrm{P}=0.001)$ (Table $1)$, with urea causing significantly greater weight loss $(\mathrm{P}<0.05)$ than the other nutrient amendments. The mean weight losses for urea, Bio-Start ${ }^{\mathrm{TM}}$, Vertex ${ }^{\mathrm{TM}}$, Simply Organic TM and water, were $29,20,20,20$ and $17 \%$, respectively. The interaction effect of nutrient amendments and fungal isolates was largely due to urea enhancing the effect of some isolates, particularly those of the genera Phoma, Epicoccum, Trichoderma, Fusarium, Ulocladium and Alternaria.

\section{DISCUSSION}

The first screen selected for isolates that were able to colonise leaf discs quickly, an important attribute in the field where they may have to compete with the primary colonisers, which use the easily degraded components within a few days. However, these primary colonisers are unable to degrade the more complex leaf components, such as the celluloses, hemicelluloses and lignins, causing them to be replaced by other fungi in succession (Frankland 1992). The second screen investigated the ability of the most effective primary colonisers to use the more complex leaf components over a longer time period. At $10^{\circ} \mathrm{C}$, the temperature that allowed greater leaf decay and provided the most appropriate comparison for winter soil temperatures in New Zealand, incubation for 9 weeks resulted in the most effective isolates of Trametes versicolor, Phoma, Epicoccum and Chaetomium spp. causing 54, 39, 37 and 23\% weight reduction, respectively. Of the nutrient amendments, only urea was more effective than the water treatment, causing $29 \%$ weight reduction overall and $43 \%$ when combined with Trametes versicolor. 
TABLE 1: Mean weight (mg) of leaf discs after inoculation with fungal isolates and 9 weeks incubation at 10 and $20^{\circ} \mathrm{C}$ (means of all leaf amendents) and five leaf amendment treatments (means of both temperatures). LSD $(P<0.05)$ values are isolates $=0.25$, temperature $=0.42$ and nutrients $=0.29$.

\begin{tabular}{|c|c|c|c|c|c|c|c|}
\hline \multirow[b]{2}{*}{ Fungal isolates } & \multicolumn{2}{|c|}{ Temperature } & \multicolumn{5}{|c|}{ Nutrient amendments } \\
\hline & $10^{\circ} \mathrm{C}$ & $20^{\circ} \mathrm{C}$ & $\begin{array}{l}\text { Simply } \\
\text { Organic }\end{array}$ & Biostart & Urea & Vertex & Water \\
\hline${ }^{2}$ Trametes versicolor (HR131) & 1.62 & 1.67 & 1.91 & 1.66 & 1.54 & 1.64 & 1.50 \\
\hline${ }^{2}$ Trametes sp. (HR163) & 1.88 & 2.31 & 2.41 & 1.90 & 2.0 & 2.10 & 2.05 \\
\hline${ }^{1}$ Phoma sp.(R236) & 2.13 & 3.02 & 2.62 & 2.58 & 2.29 & 2.72 & 2.66 \\
\hline${ }^{2}$ Epicoccum sp.(E062) & 2.22 & 2.83 & 2.33 & 2.61 & 2.14 & 2.74 & 2.80 \\
\hline${ }^{1}$ Phoma sp.( R 237) & 2.24 & 2.97 & 2.85 & 2.57 & 2.35 & 2.71 & 2.54 \\
\hline${ }^{2}$ Epicoccum sp.(E083) & 2.44 & 2.91 & 2.82 & 2.66 & 2.45 & 2.65 & 2.80 \\
\hline${ }^{1}$ Fusarium sp.(R118) & 2.55 & 3.05 & 2.89 & 2.92 & 2.24 & 3.12 & 2.84 \\
\hline${ }^{1}$ Fusarium sp.(R119) & 2.58 & 3.02 & 2.88 & 2.88 & 2.52 & 2.65 & 3.07 \\
\hline${ }^{1}$ Ulocladium sp.(R229) & 2.66 & 3.05 & 3.36 & 3.05 & 2.72 & 3.11 & 3.35 \\
\hline${ }^{2}$ Trichoderma sp.(trispp04) & 2.67 & 2.92 & 2.87 & 2.85 & 2.38 & 3.08 & 3.11 \\
\hline${ }^{3}$ Chaetomium sp.(CG1) & 2.69 & 3.13 & 2.89 & 2.90 & 2.62 & 2.90 & 3.98 \\
\hline${ }^{1}$ Alternaria sp.(R42) & 2.70 & 3.42 & 2.95 & 3.05 & 2.54 & 3.02 & 2.90 \\
\hline${ }^{1}$ Alternaria sp.(R63) & 2.73 & 3.21 & 3.22 & 3.11 & 2.64 & 3.28 & 3.05 \\
\hline${ }^{1}$ Trichoderma sp.(R132) & 2.73 & 3.05 & 2.65 & 2.84 & 2.55 & 3.11 & 2.82 \\
\hline${ }^{3}$ Chaetomium sp. (CG5) & 2.85 & 2.87 & 3.21 & 3.28 & 3.40 & 2.97 & 3.27 \\
\hline${ }^{1}$ Aureobasidium sp.(R126) & 2.94 & 3.50 & 3.05 & 2.92 & 2.75 & 3.24 & 2.86 \\
\hline${ }^{1}$ Aureobasidium sp.(R113) & 3.10 & 3.40 & 3.62 & 3.10 & 3.24 & 3.19 & 3.11 \\
\hline${ }^{2}$ Ulocladium sp.(U015) & 3.14 & 3.22 & 3.05 & 2.97 & 2.81 & 2.72 & 3.01 \\
\hline Mean of isolates & 2.55 & 2.98 & 2.87 & 2.77 & 2.51 & 2.83 & 2.87 \\
\hline
\end{tabular}

Sources of cultures were ${ }^{1} \mathrm{R}$. Bakker, Lincoln University, ${ }^{2}$ HortResearch Lincoln, ${ }^{3}$ Plant Pathology Group, Lincoln University.

The genera that performed well in this study were also found to be effective in a similar study by Philion et al. (1997). In their study, isolates of Phoma, Epicoccum, Fusarium, Trichoderma and Chaetomium, were effective at reducing the strength of apple leaf discs by 42, 41, 29, 18 and $21 \%$, respectively and also inhibited ascospore production by $V$. inaequalis by $41,38,26,19$ and $13 \%$, respectively. In dual agar plate studies and investigations using culture filtrates, Ouimet et al. (1997) also found that isolates of the same genera had antagonistic properties, preventing mycelial growth of $V$. inaequalis. Although Chaetomium isolates did not perform as well as other isolates in this and other laboratory studies, in other field studies C. globosum was found to consistently and effectively reduce ascospore numbers (Cullen et al. 1985). The whiterot fungi, which include the Trametes spp., are common saprophytes in many types of litter and very rapidly degrade cellulose, hemicellulose and lignin (Rihani et al. 1995), although there are no reports of their use in control of $V$. inaequalis, possibly because of their potential pathogenic characteristics. However, their efficacy in this trial indicate that trials should be conducted to verify their activity under field conditions, before pathogenicity trials are conducted to check the safety of the isolates used.

These results indicate that some New Zealand isolates of saprophytic fungi are likely to be effective in enhancing leaf degradation. Future field trials will evaluate the isolates of Trametes versicolor (HR131), Phoma (R236), Epicoccum (E062) and Chaetomium (CG1), and the leaf amendments, urea and the mixed Bio-Start ${ }^{\mathrm{TM}}$ products, as overwintering treatments on apple leaf litter for reduction of ascospore numbers in spring. 


\section{REFERENCES}

Beresford, R.M.; Manktelow, D.W.L. 1994: Economics of reducing fungicide use by weather-based disease forecasts for control of Venturia inaequalis in apples. N.Z. J. Crop Hort. Sci. 22: 113-120.

Beresford, R.M.; Horner, I.J.; Wood, P.N. 2000: Autumn-applied urea and other compounds to suppress Venturia inaequalis ascospore production. Proc. $53^{\text {rd }}$ N.Z. Plant Prot. Conf.: 387-392.

Burchill, R.T. 1968: Field and laboratory studies of the effect of urea on ascospore production of Venturia inaequalis (Cke) Wint. Annals Appl. Biol. 62: 297-307.

Carisse, O.; Philion, V.; Rolland, D.; Bernier, J. 2000: Effect of fall application of fungal antagonists on spring ascospore production of the apple scab pathogen, Venturia inaequalis. Phytopath. 90: 31-37

Cullen, D.; Berbee, F.M.; Andrews J.H. 1985: Chaetomium globosum antogonises the apple scab pathogen, Venturia inaeqaulis, under field conditions. Can. J. Bot. 62: 1814-1818.

Frankland, J.C. 1992: Mechanisms in fungal succession. In: Carroll, G.C. Wicklow, D.T. $e d$. The Fungal Community: Its Organisation and Role in the Ecosystem, $2^{\text {nd }}$ ed. Marcel Decker, New York. Pp. 383-401.

MacHardy, W.E. 1996: Apple Scab, Biology, Epidemiology, and Management. American Phytopathological Society Press, Minnesota, USA. 310 p.

Ouimet, A.; Carisse, O.; Neuman, P. 1997: Evaluation of fungal isolates for the inhibition of vegetative growth of Venturia inaequalis. Can. J. Bot. 75: 626-631

Philion, V.; Carisse, O.; Paulitz, T. 1997: In vitro evaluation of fungal isolates for their ability to influence leaf rheology, production of psuedothecia, and ascospores of Venturia inaequalis. European J. Plant Path. 103: 441-452.

Rihani, M.; Kiffer, E.; Botton, B. 1995: Decomposition of beech leaf litter by microflora and mesofauna. I. In vitro action of white rot fungi on beech leaves and foliar components. European J. Soil Biol. 31: 57-66. 